\title{
SARS-CoV-2 testing and infection control strategies in European paediatric emergency departments during the first wave of the pandemic
}

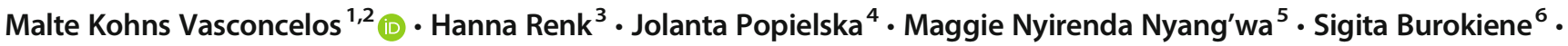 \\ Despoina Gkentzi ${ }^{7}$. Ewelina Gowin ${ }^{8} \cdot$ Daniele Donà $^{9} \cdot$ Sara Villanueva-Medina $^{10}$. Andrew Riordan ${ }^{11}$. \\ Markus Hufnagel $^{12}$. Sarah Eisen ${ }^{13}$. Liviana Da Dalt ${ }^{14}$. Carlo Giaquinto ${ }^{9}$. Julia A. Bielicki ${ }^{1,15}$
}

Received: 11 June 2020 /Revised: 1 September 2020 / Accepted: 9 October 2020 / Published online: 13 October 2020

(C) The Author(s) 2020

\begin{abstract}
Between February and May 2020, during the first wave of the COVID-19 pandemic, paediatric emergency departments in 12 European countries were prospectively surveyed on their implementation of SARS-CoV-2 disease (COVID-19) testing and infection control strategies. All participating departments (23) implemented standardised case definitions, testing guidelines, early triage and infection control strategies early in the outbreak. Patient testing criteria initially focused on suspect cases and later began to include screening, mainly for hospital admissions. Long turnaround times for test results likely put additional strain on healthcare resources.

Conclusion: Shortening turnaround times for SARS-CoV-2 tests should be a priority. Specific paediatric testing criteria are needed.
\end{abstract}

What is Known:

- WHO and public health authorities issued case definitions, testing and infection control recommendations for COVID-19 in January.

- SARS-CoV-2 testing was made available across Europe in February.

What is New:

- Paediatric emergency departments implemented COVID-19-specific procedures rapidly, including case definitions, testing guidelines and early triage.

- A third of surveyed departments waited more than 24 h for SARS-CoV-2 test to be reported, resulting in additional strain on resources.

Keywords COVID-19 $\cdot$ Preparedness $\cdot$ Survey $\cdot$ Triage

Communicated by Nicole Ritz

Malte Kohns Vasconcelos

Malte.KohnsVasconcelos@med.uni-duesseldorf.de

Hanna Renk

Hanna.Renk@med.uni-tuebingen.de

Jolanta Popielska

jolanta.popielska@wum.edu.pl

Maggie Nyirenda Nyang’wa

mnyirenda@nhs.net

Sigita Burokiene

sigita.burokiene@santa.lt

Despoina Gkentzi

gkentzid@hotmail.com

Ewelina Gowin

ewego@ump.edu.pl

Daniele Donà

daniele.dona@phd.unipd.it
Sara Villanueva-Medina

s.villanuevamedina@gmail.com

Andrew Riordan

Andrew.Riordan@alderhey.nhs.uk

Markus Hufnagel

markus.hufnagel@uniklinik-freiburg.de

Sarah Eisen

sarah.eisen@nhs.net

Liviana Da Dalt

liviana.dadalt@unipd.it

Carlo Giaquinto

carlo.giaquinto@unipd.it

Julia A. Bielicki

jbielick@sgul.ac.uk

Extended author information available on the last page of the article 


$\begin{array}{ll}\text { Abbreviations } & \\ \text { A\&E } & \text { Accident and emergency department } \\ \text { ARI } & \text { Acute respiratory infection } \\ \text { ECDC } & \begin{array}{l}\text { European Centre for Disease } \\ \text { Prevention and Control }\end{array} \\ \text { HSCT } & \begin{array}{l}\text { Haematopoietic stem cell transplantation } \\ \text { LRTI }\end{array} \\ \text { Lower respiratory tract infection } \\ \text { PICU } & \text { Paediatric intensive care unit } \\ \text { SARS-CoV-2 } & \text { Severe acute respiratory syndrome } \\ & \text { coronavirus 2 } \\ \text { UK } & \text { United Kingdom } \\ \text { WHO } & \text { World Health Organization }\end{array}$

\section{Background}

European reference laboratories established widespread capacities for testing for severe acute respiratory syndrome coronavirus 2 (SARS-CoV-2) within a matter of days after a diagnostic test was made publicly available $[1,2]$. World Health Organization (WHO) and public health authorities in Europe issued case definitions, testing and infection control recommendations for COVID-19 in January 2020.

The current understanding of COVID-19 in paediatric patients is that children more often have mild disease compared to adults [3, 4]. Current knowledge suggests that the peak of infectiousness of SARS-CoV-2 infection occurs a few days before and after the onset of symptoms, meaning that presymptomatic people are able to transmit the infection [5]. Transmission unobserved by public health authorities occurs frequently, with at least one-third of cases having been undetected during the early epidemic $[6,7]$.

The aim of this study was to describe the implementation of testing and infection control strategies and their evolution in paediatric emergency departments in Europe.

\section{Methods}

From mid-February to the first week of May 2020, we surveyed all European paediatric collaboration sites within the PENTA ID paediatric research network weekly for developments in their testing and infection control strategies. Portable document format (pdf) survey forms were sent out by email to contact officers at 78 paediatric departments across Europe. The survey form is available as an online supplement to this article. Completed and signed survey forms were handed in by return email. Missing weekly replies were imputed as last observation carried forward.

\section{Results}

Paediatric departments of 23 mostly tertiary care hospitals in 12 European countries (Belgium, Germany, France, Italy, Poland, Portugal, the UK, the Netherlands, Greece, Spain, Lithuania and Switzerland) participated in the surveys (response rate 29\%). Multiple sites participated in the UK (5, 3 tertiary and 2 secondary level), Germany (5, 4 tertiary and 1 secondary level), Spain (3, 1 network of sites representing the Madrid region, 1 tertiary and 1 secondary level) and Poland (2, both tertiary level). In each of the remaining countries (Belgium, France, Italy, Portugal, the Netherlands, Greece, Lithuania and Switzerland), one site participated.

\section{Rapid implementation and evolution of standardised case definitions}

By the end of February 2020, all hospitals had implemented standardised case definitions for suspected COVID-19 cases, with the majority (16 out of 21 participating at that point in time, $76 \%$ ) following national government or public health authority guidelines and three directly following WHO guidelines. Standardised definitions of suspected cases showed high similarity between sites. All definitions consisted of a clinical component of acute respiratory infection and an epidemiological component of possible exposure to the virus. The latter changed between February and April: initially, definitions at all sites required contact within 14 days with a confirmed case or travel to specified geographic areas; in time, this changed to staying in any area with ongoing community transmission. Twenty participating sites used suspected case definitions from the beginning that did not exclude patients on detection of an alternative pathogen. Two of the Spanish sites and one site in Poland initially excluded patients with confirmed alternative diagnoses of respiratory infections from being suspect cases for COVID-19. This changed by April at all three sites, so that afterwards detection of another pathogen that could explain the respiratory symptoms no longer excluded a patient from being a suspect case and from undergoing SARS-CoV-2 testing.

\section{Strict testing guidelines in line with case definitions}

Ten sites $(43 \%)$ reported that they strictly only tested patients for SARS-CoV-2 if they matched the definition of a suspected case. Another $12(52 \%)$ had a policy to only test patients matching the case definition but reported that exceptions occurred regularly. Until April, no site reported that their decision to test patients was based on separate local guidelines. In April, several German and UK sites started broader testing, first with testing of patients admitted to oncology or intensive care units and from the end of April with routine screening of all admitted patients. Table 1 shows example developments of testing guidelines at four participating children's emergency departments. 


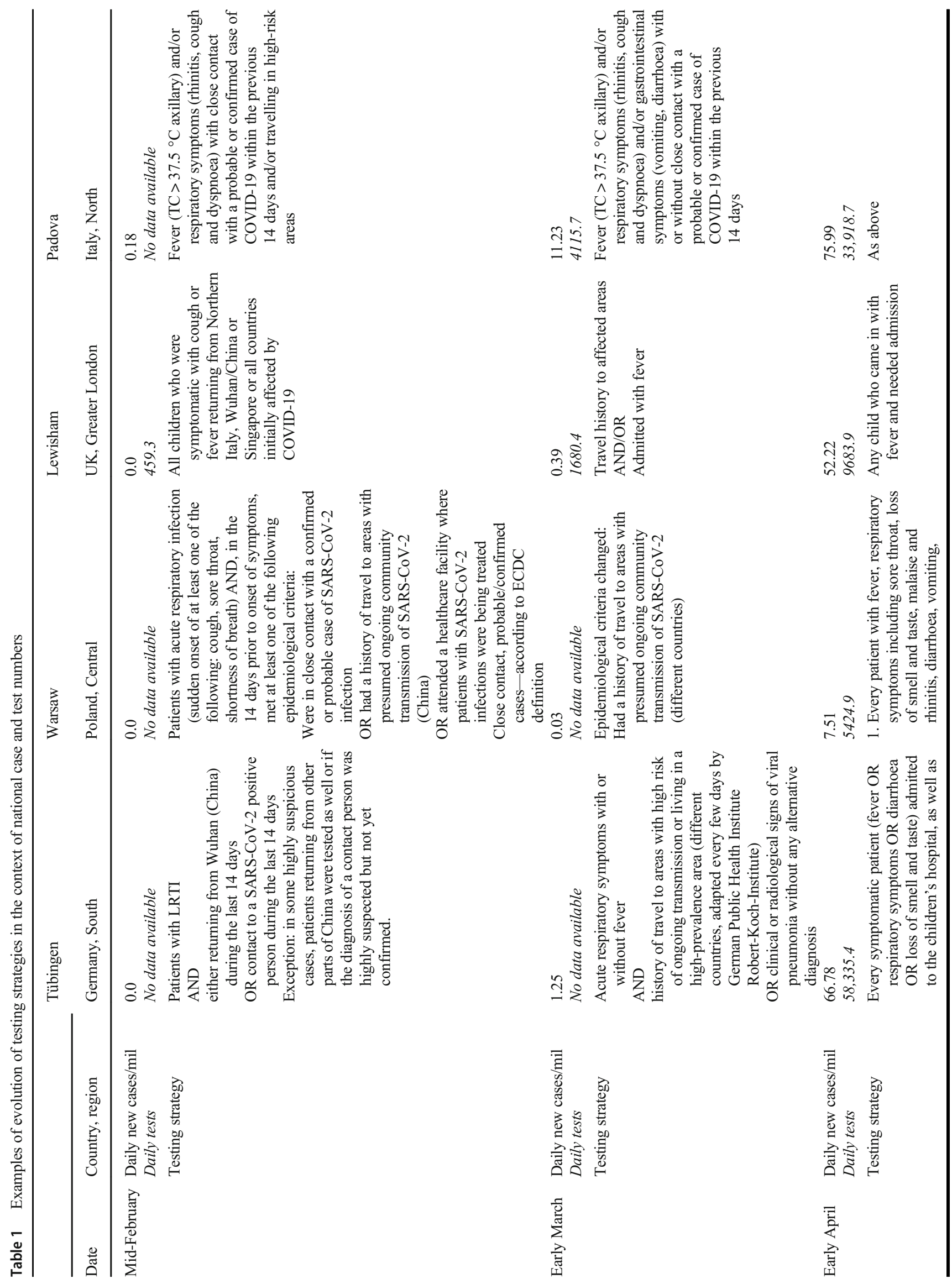



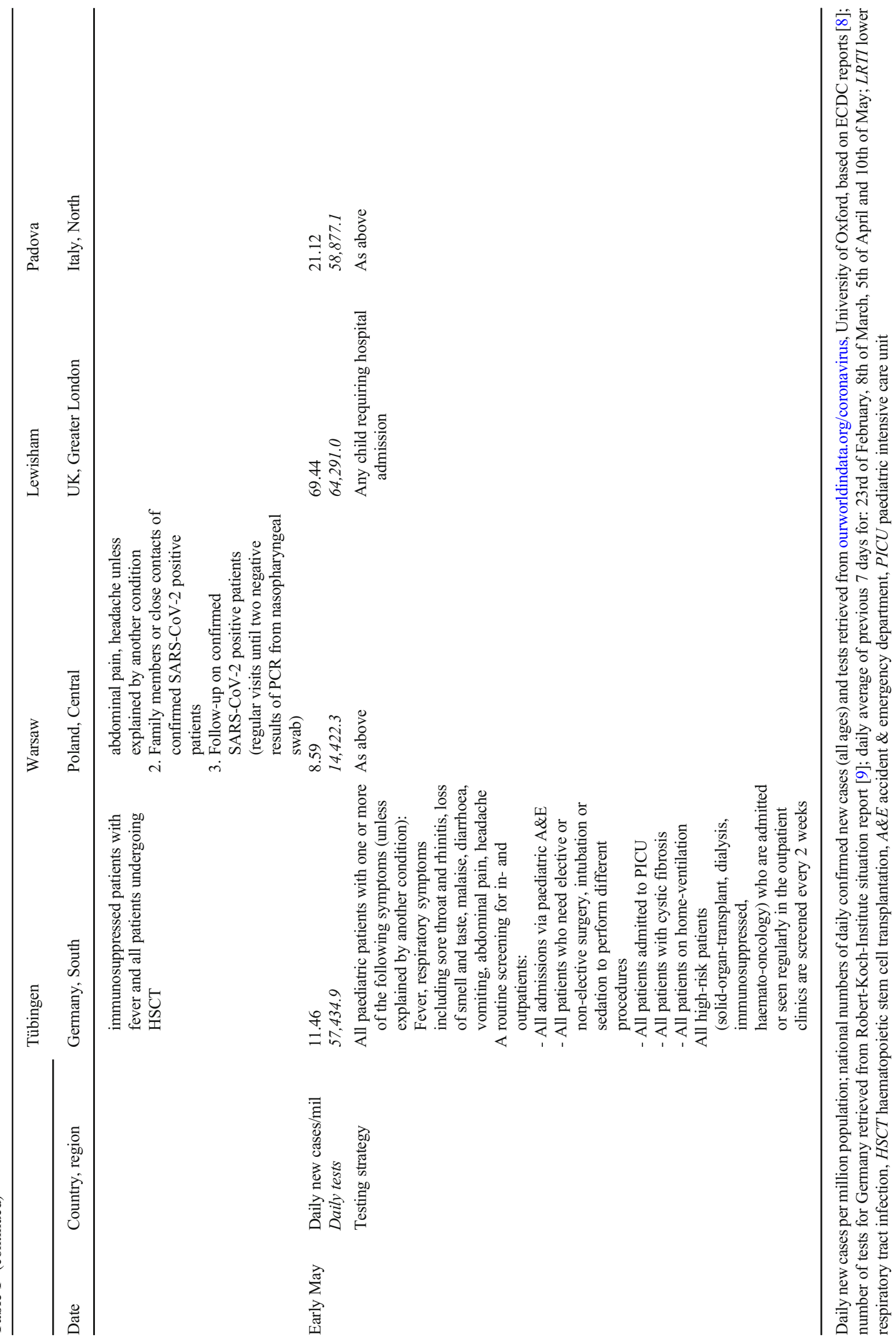
In terms of sampling site, $52 \%$ of the participating hospitals restricted testing to upper respiratory samples, while $48 \%$ obtained upper and lower respiratory samples if the latter could be obtained.

Although discharge and infection control strategies after admission relied heavily on test results, by the end of the survey period only 9 hospitals (39\%) received test results multiple times daily, while another $7(30 \%)$ had waiting times of more than $24 \mathrm{~h}$ before test results would be back. At all but two sites, where faster turnaround times could be achieved, expected time to test results did not change over the survey period. By the beginning of March, $9(43 \%)$ were discharging patients with pending test results when they were clinically stable. Three of the seven hospitals where results took more than $24 \mathrm{~h}$ to come back would not discharge patients while test results were pending, regardless of whether the patients were clinically stable. By mid-March all hospitals were discharging patients with pending test results.

Until the beginning of March, sites saw up to 30 suspected cases per week. While only one site (in Germany) had a child positive for SARS-CoV-2, 67\% of sites had already provided care to suspected cases of SARS-CoV-2. At the different sites, the highest number of patients tested per week differed widely between 7 per week for a secondary care hospital in Western Germany and 112 for a specialised tertiary care children's hospital in North England. Community test centres for COVID-19 opened across Germany in early to mid-March and in the UK only in April. Opening of community test centres in proximity to the surveyed sites coincided with varying stages of development of overall case numbers in the areas. Therefore, our data allow no firm conclusion on whether opening of community test centres alleviated patient pressure on paediatric emergency departments.

\section{Rapid implementation of infection control strategies}

Most departments used early clinical triage at the emergency department to separate suspected cases from other patients from the beginning of the survey period. Only one site (in Greece) initially did not triage but changed this in the last week of February. Two UK hospitals had plans to refer patients with positive test results to other hospitals for admission, and eight hospitals were planning to place multiple patients tested positive in cohort isolation if limited capacity for individual isolation occurred.

At most hospitals, staff used respirators, i.e. filtering face piece (FFP) masks, when treating suspected cases in the emergency department. In contrast, staff at four UK sites, in the Netherlands and at one site in Poland used surgical masks only. This did not change over the survey period.

\section{Discussion}

In the early stages of the COVID-19 pandemic, paediatric emergency departments implemented standardised case definitions, testing guidelines and infection control measures rapidly. While this is an important and reassuring finding regarding the preparedness of paediatric emergency care in Europe, it may be a limitation of this survey that our sample of hospitals was biased towards tertiary care hospitals with strong international research links.

Although infection control strategies and even discharge of patients relied heavily on receiving SARSCoV-2 test results, most hospitals only received these after considerable delay, often more than $24 \mathrm{~h}$. Shortening turnaround times for tests should be a priority. Prior to discharge, infection control measures on uninfected patients awaiting test results place a huge burden on emergency care resources. Most departments rightly responded by discharging patients while test results were pending. This does not, however, mitigate against the public health impact of delayed result reporting on efficient contact tracing and subsequent isolation or quarantine of contacts in the community.

The guidelines for testing focused on two aims: establishing aetiology in children with symptoms of ARI and excluding infection for inpatient infection control purposes. This was a necessary restriction while numbers of new infections were high and capacities for testing were limited. We believe that in the current situation with vastly expanded laboratory capacities, a broader approach with more testing of mildly symptomatic patients or asymptomatic contacts may be warranted. To allocate testing resources responsibly, we believe that specific testing criteria for the paediatric population are needed because both the individual risk of children to suffer from severe disease and to sustain transmission in the community differ from that in adults $[10,11]$.

Children and adolescents suffer serious consequences from school closures and allowing schools to re-open has positive social, psychological and economic implications [12]. Benefits of broader access to testing may include the ability to detect outbreaks in day care facilities and schools earlier in order to limit spread of infections while maintaining as much normality as possible for children and adolescents.

Acknowledgements The authors would like to thank the following people for the kind contribution of survey data: Tessa Goetghebuer, CHU Saint-Pierre, Brussels, Belgium; Francois Dubos, CHU Lille, France; Pieter Fraaij, Sophia Children's Hospital, EMC Rotterdam, the Netherlands; Andrés Anton, Vall d'Hebron University Hospital, Barcelona, Spain; Robin Kobbe, Kinder-UKE, Hamburg, Germany; Christian Schmidt, St. Vinzenz Hospital Dinslaken, Germany; Arnaud L'Huiller, CHU Genève, Switzerland; Emma Gardiner, University Hospital Lewisham, London, UK; Alexandre Fernandes, Centro Hospitalar e Universitário do Porto, Portugal. 
Authors' contributions MKV, CG and JAB designed the study, all authors commented on the design; CG provided resources for the survey; MKV received and analysed the survey forms; MKV, HR, JP, MNN, DD and $\mathrm{JAB}$ wrote the manuscript; $\mathrm{SB}, \mathrm{EG}$ and $\mathrm{AR}$ revised the manuscript; all authors commented on the manuscript and approved the final version.

Funding Open Access funding enabled and organized by Projekt DEAL.

\section{Compliance with ethical statements}

Conflict of interest The authors declare that they have no conflict of interest.

Ethical approval The survey was considered a clinical audit. This article does not contain any studies with human participants or animals performed by any of the authors.

Open Access This article is licensed under a Creative Commons Attribution 4.0 International License, which permits use, sharing, adaptation, distribution and reproduction in any medium or format, as long as you give appropriate credit to the original author(s) and the source, provide a link to the Creative Commons licence, and indicate if changes were made. The images or other third party material in this article are included in the article's Creative Commons licence, unless indicated otherwise in a credit line to the material. If material is not included in the article's Creative Commons licence and your intended use is not permitted by statutory regulation or exceeds the permitted use, you will need to obtain permission directly from the copyright holder. To view a copy of this licence, visit http://creativecommons.org/licenses/by/4.0/.

\section{References}

1. Reusken C, Broberg EK, Haagmans B, Meijer A, Corman VM, Papa A, Charrel R, Drosten C, Koopmans M, Leitmeyer K, On Behalf Of E-L, Erli N (2020) Laboratory readiness and response for novel coronavirus (2019-nCoV) in expert laboratories in $30 \mathrm{EU} /$ EEA countries, January 2020. Eurosurveillance 25(6). https://doi. org/10.2807/1560-7917.es.2020.25.6.2000082

2. Corman VM, Landt O, Kaiser M, Molenkamp R, Meijer A, Chu DK, Bleicker T, Brunink S, Schneider J, Schmidt ML, Mulders DG, Haagmans BL, van der Veer B, van den Brink S, Wijsman L, Goderski G, Romette JL, Ellis J, Zambon M, Peiris M, Goossens H, Reusken C, Koopmans MP, Drosten C (2020) Detection of 2019 novel coronavirus $(2019-\mathrm{nCoV})$ by real-time RT-PCR. Eurosurveillance 25(3). https://doi.org/10.2807/1560-7917.es. 2020.25.3.2000045

3. Zimmermann P, Curtis N (2020) Coronavirus infections in children including COVID-19: an overview of the epidemiology, clinical features, diagnosis, treatment and prevention options in children. Pediatr Infect Dis J 39(5):355-368. https://doi.org/10.1097/inf. 0000000000002660

4. Ludvigsson JF (2020) Systematic review of COVID-19 in children shows milder cases and a better prognosis than adults. Acta Paediatr 109(6):1088-1095. https://doi.org/10.1111/apa.15270

5. He X, Lau EHY, Wu P, Deng X, Wang J, Hao X, Lau YC, Wong JY, Guan Y, Tan X, Mo X, Chen Y, Liao B, Chen W, Hu F, Zhang Q, Zhong M, Wu Y, Zhao L, Zhang F, Cowling BJ, Li F, Leung GM (2020) Temporal dynamics in viral shedding and transmissibility of COVID-19. Nat Med 26(5):672-675. https://doi.org/10. 1038/s41591-020-0869-5

6. Walker A, Houwaart T, Wienemann T, Kohns Vasconcelos M, Strelow D, Senff T, Hülse L, Adams O, Andree M, Hauka S, Feldt T, Jensen B-E, Keitel V, Kindgen-Milles D, Timm J, Pfeffer K, Dilthey AT (2020) Genetic structure of SARS-CoV-2 reflects clonal superspreading and multiple independent introduction events, North-Rhine Westphalia, Germany, February and March 2020. Eurosurveillance 25(22):2000746. https://doi.org/10. 2807/1560-7917.ES.2020.25.22.2000746

7. Giordano G, Blanchini F, Bruno R, Colaneri P, Di Filippo A, Di Matteo A, Colaneri M (2020) Modelling the COVID-19 epidemic and implementation of population-wide interventions in Italy. Nat Med 26:855-860. https://doi.org/10.1038/s41591-020-0883-7

8. Roser M, Ritchie H, Ortiz-Ospina E, Hasell J, Oxford Martin School (2020) Coronavirus Country Profiles. www. ourworldindata.org/coronavirus. Accessed 28 May 2020

9. Robert-Koch-Institut (2020) Aktueller Lage-/Situationsbericht des RKI zu COVID-19. https://www.rki.de/DE/Content/InfAZ/N/ Neuartiges_Coronavirus/Situationsberichte/Gesamt.html. Accessed 28 May 2020

10. Merckx J, Labrecque JA, Kaufman JS (2020) Transmission of SARS-CoV-2 by children. Dtsch Arztebl Int 117(33-34):553560. https://doi.org/10.3238/arztebl.2020.0553

11. Götzinger F, Santiago-García B, Noguera-Julián A, Lanaspa M, Lancella L, Calò Carducci FI, Gabrovska N, Velizarova S, Prunk P, Osterman V, Krivec U, Lo Vecchio A, Shingadia D, SorianoArandes A, Melendo S, Lanari M, Pierantoni L, Wagner N, L'Huillier AG, Heininger U, Ritz N, Bandi S, Krajcar N, Roglić S, Santos M, Christiaens C, Creuven M, Buonsenso D, Welch SB, Bogyi M, Brinkmann F, Tebruegge M (2020) COVID-19 in children and adolescents in Europe: a multinational, multicentre cohort study. Lancet Child Adolesc Health 4(9):653-661. https://doi.org/ 10.1016/s2352-4642(20)30177-2

12. Schober T, Rack-Hoch A, Kern A, von Both U, Hübner J (2020) Coronakrise: Kinder haben das Recht auf Bildung. Dtsch Arztebl 117(19):A990-A994

Publisher's note Springer Nature remains neutral with regard to jurisdictional claims in published maps and institutional affiliations. 


\section{Affiliations}

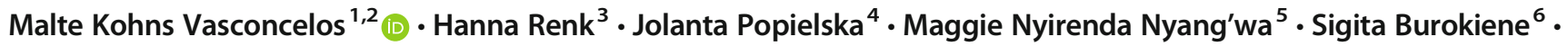
Despoina Gkentzi ${ }^{7}$. Ewelina Gowin ${ }^{8}$. Daniele Donà ${ }^{9}$ - Sara Villanueva-Medina ${ }^{10}$. Andrew Riordan ${ }^{11}$. Markus Hufnagel $^{12} \cdot$ Sarah Eisen $^{13} \cdot$ Liviana Da Dalt $^{14} \cdot$ Carlo Giaquinto $^{9} \cdot$ Julia A. Bielicki ${ }^{1,15}$

1 Paediatric Infectious Diseases Research Group, Institute for Infection and Immunity, St. George's, University of London, London, UK

2 Institute for Medical Microbiology and Hospital Hygiene, Heinrich Heine University Düsseldorf, Universitätsstr. 1, 40225 Düsseldorf, Germany

3 Department of Paediatric Cardiology, Pulmonology and Intensive Care Medicine, University Children's Hospital Tübingen, Tübingen, Germany

4 Department of Children's Infectious Diseases Medical University of Warsaw, Infectious Diseases Hospital in Warsaw, Warsaw, Poland

5 Paediatric Department, University Hospital Lewisham, London, UK

6 Clinic of Children's Diseases, Institute of Clinical Medicine, Vilnius University, Vilnius, Lithuania

7 Department of Paediatrics, Patras Medical School, University General Hospital of Patras, Patras, Greece

8 Department of Health Promotion, Poznan University of Medical Sciences, Poznan, Poland
9 Division of Paediatric Infectious Diseases, Department of Women's and Children's Health, University Hospital of Padua, Padua, Italy

10 Pediatric Infectious Diseases Unit, Department of Pediatrics, Hospital Universitario 12 de Octubre, Madrid, Spain

11 Department of Paediatric Infectious Diseases, Alder Hey Children's Hospital, Liverpool, UK

12 Division of Pediatric Infectious Diseases and Rheumatology, Department of Pediatrics and Adolescent Medicine, University Medical Center, Medical Faculty University of Freiburg, Freiburg, Germany

13 Department of Paediatrics, University College London Hospital Foundation Trust, London, UK

14 Pediatric Emergency Unit, Department of Women's and Children's Health, University Hospital of Padua, Padua, Italy

15 Department of Infectious Diseases and Vaccinology, University of Basel Children's Hospital (UKBB), Basel, Switzerland 